\title{
LA REVISIÓN DE LOS TEMAS DE LA ANTIGÜEDAD EN LA PINTURA DE HISTORIA ESPAÑOLA DEL SIGLO XIX: ENTRE LA EVOCACIÓN DEL PASADO Y LA LEGITIMACIÓN DEL PODER
}

\author{
Review of Topics of the Ancient History in Spanish Painting of the Nineteenth Century: \\ Between the Evocation of past and the Legitimation of Power
}

\author{
María Victoria ÁlVAREZ RODRÍGUEZ \\ Universidad de Salamanca \\ E-mail: u58488@usal.es
}

Fecha de recepción: 18-01-2010

Fecha de aceptación: 29-01-2010

\begin{abstract}
RESUMEN: Tradicionalmente se ha considerado la pintura de historia como la parcela más importante de las artes plásticas del siglo XIX. Tanto en el Neoclasicismo como en el Romanticismo, y hasta más adelante, en pleno Realismo, se convirtió en una especie de escaparate de los avances técnicos y compositivos que caracterizaron la evolución del arte de esta centuria, así como de sus presupuestos teóricos y el aliento estético de sus obras.

Pero esta misma evolución también se percibió en los propios temas que se representaron. La Antigüedad, entendida como un modelo de virtud, tanto artística como política, presidió buena parte de las creaciones de nuestros pintores. La repetición de temas heroicos como la caída de Numancia y de Sagunto se convirtió en una constante, deviniendo en un hito en la Historia del Arte. Nos proponemos estudiar la incidencia que alcanzaron estas representaciones de la Antigüedad a nivel nacional, una muestra de cómo los artistas españoles supieron prestar su personalidad a un género pictórico que se suele considerar eminentemente europeo en cuanto a sus orígenes, evolución y características.
\end{abstract}

Palabras Clave: Antigüedad, Siglo XIX, Pintura, Historia, España

ABSTRACT: Traditionally it has been considered history painting as the most important piece of the plastic arts of the nineteenth century. In both, Neoclassicism and Romanticism, 
and even later, in the Realism, became a showcase of technical advances and compositional trends that characterized the trend of the art of this century, and its theoretical assumptions and encouragement aesthetics of their works.

But this same trend was seen also in the very subjects that were represented. Antiquity, understood as a model of virtue, both artistically and politically, presided over much of the creations of our painters. The repetition of heroic themes as the fall of Numancia and Sagunto became a constant, becoming a landmark in the history of art. We intend to examine the implications that reached these representations of antiquity into the national level, a sample of how Spanish artists knew how to lend their personality to a genre of painting that is often seen predominantly European in their origins, evolution and characteristics.

Keywords: Antiquity, XIXth Century, Painting, History, Spain

A la hora de estudiar la influencia ejercida por la Antigüedad sobre la Historia del Arte, y sobre la misma Historia de la humanidad, solemos encontrarnos con numerosos tópicos relacionados con el supuesto abandono en que permanecieron los conocimientos del Mundo Clásico durante los "siglos de oscuridad" de la Edad Media. Sabemos que se trata de una valoración inexacta, aunque sí es cierto que Europa tuvo que esperar hasta el Renacimiento para que resurgieran con la debida intensidad los presupuestos que habían sido característicos de la época, tal como sucedió posteriormente con el Neoclasicismo.

En los siglos XV y XVI ya se habían llevado a cabo numerosas excavaciones en la Ciudad Eterna que permitieron conocer de primera mano manifestaciones artísticas tan trascendentales de cara a la Historia del Arte como el Laocoonte ${ }^{1}$, aunque las empresas de mayor repercusión se acometieron a fines del siglo XVIII. En sus últimas décadas, entre las postrimerías del Barroco y los comienzos de una nueva centuria, se tomaron como modelos a seguir los hallazgos de Pompeya y Herculano que permitieron que se pudiera considerar la arqueología como una ciencia de pleno derecho². Pronto las formas que se habían tenido por las más adecuadas, dentro del panorama de la construcción, quedaron obsoletas; los monumentos greco-romanos se pusieron por delante de cualquier fuente de inspiración que hubieran manejado los artistas, la pureza y simetría de la arquitectura sustituyeron al horror vacui de las iglesias y retablos barrocos, y la sencillez se instaló en el trono de los derroches decorativos que se habían dado hasta entonces. Algo similar sucedió con el propio trono de España, con la dinastía de los Borbones sustituyendo a la de los Habsburgo, y trayendo consigo la influencia de gran parte de las corrientes que se seguían propagando por Europa en las mismas fechas, en especial por Italia y Francia. 
La mayoría de las creaciones de comienzos del siglo XIX se mantenía en la estela clásica promulgada por los estetas, filósofos e historiadores, que apostaban por una continuación de los conocidos cánones de belleza establecidos en la Antigüedad. Construcciones como el Walhalla de Leo von Klenze, esculturas como Eros y Psique de Antonio Canova y pinturas como El juramento de los Horacios de Jacques-Louis David son testimonios de hasta qué punto se encontraban estos presupuestos artísticos en boga. En el caso de España, habría que esperar varias décadas para que penetraran con tanta fuerza como en el resto de Europa, siendo la pintura de historia una excelente receptora.

No debemos confundirnos a este respecto; aunque la pintura de historia española del siglo XIX haya alcanzado las cotas más altas que se podían dar dentro de este género, su surgimiento se sitúa mucho antes, en los ejercicios académicos en los que se imponía a un grupo de jóvenes artistas un tema normalmente de contenido moralizante, a la par que político. Remontarse hasta los momentos más trascendentes de la historia del país parecía lo más natural, algo en lo que tuvo mucho que ver el creciente patriotismo que se convirtió en uno de los rasgos de personalidad del siglo XIX. Así, los exámenes de promoción de instituciones como la Real Academia de Bellas Artes de San Fernando nos han proporcionado un elevadísimo número de lienzos relacionados con la toma de Granada, la invasión de Napoleón, las caídas de Numancia y Sagunto. Son precisamente estos temas de carácter clásico los que más nos servirán de cara a nuestro estudio, por remontarse a la Antigüedad sin dejar de lado las exigencias que se esperaban del género.

Uno de los puntos principales, tal vez el que más contaba en las exposiciones, era el afán de verosimilitud del episodio representado. Para lograrlo los artistas realizaban pormenorizados estudios de los aderezos, vestidos y mobiliario de la época que pudieran conservarse, además de sumergirse en la lectura de manuales de historia que les sirvieran como medio de documentación. Los testimonios de autores latinos, las crónicas de los reyes de la Edad Media como Alfonso X el Sabio y algunos escritos del Renacimiento se cuentan entre las fuentes más consultadas, pero la palma se la llevaron, sin duda, textos contemporáneos como las Historias Generales de España del padre Mariana y Modesto Lafuente, las Vidas de españoles célebres de Quintana y demás ejemplos de la mano de Cavanilles, Gebhardt y Castillo ${ }^{3}$. La consideración de "pintura de historia" no podía resultar más apropiada; la erudición de estos pintores se consideraba un requisito sine qua non a la hora de acometer una composición que les permitiera granjearse los laureles de la fama. Francisco de Mendoza, autor de otro renombrado manual, sostenía:

Es menester así que se ha escogido el asunto, leerlo muchas veces hasta dominarlo bien y saberlo de memoria, no concretándose sólo al párrafo que lo describe, 
sino leyendo toda la parte anterior y posterior por lo menos desde que el personaje o personajes que constituyen el asunto elegido empezaron a figurar en la historia de que se trata. ${ }^{4}$

La importancia de una correcta plasmación de los detalles no se basa solamente en la necesidad de crear una buena obra, sino de convertirla en un instrumento moralizante para una nueva época. Los temas del pasado se retoman como ejemplos vivos de un modelo de conducta de cara a la sociedad española del siglo XIX; así pues, la verosimilitud resultaba necesaria a la fuerza. "El verdadero cuadro de historia se funda siempre en un hecho de capital importancia para un país o una raza", sostenía Jacinto Octavio Picón, un crítico de la época, "en un momento determinado y preciso en que el esfuerzo de un hombre o de un pueblo realiza algo que influye poderosamente en la vida social"'5. Los propios pintores de historia, como Casado del Alisal, incidieron sobre este mismo punto:

¿No experimentáis un legítimo sentimiento de orgullo ante este floreciente estado de la pintura española, que cultiva todos los campos, desde el elevado y severo de la pintura de historia, maestra de las multitudes, cuya educación completa y cuyo espíritu enaltece por la representación de los grandes sucesos y de los grandes héroes, hasta los cuadros de costumbres y vida íntima? ${ }^{3}$

De esta manera, las gestas de nuestro pasado se perpetuaban en la pintura como ya estaba sucediendo en la literatura, en las mismas fechas. Algunos temas como el arrojo ante la proximidad de la muerte, el sentimiento trágico de la vida y el dolor producido por un amor imposible se convirtieron en una constante, pero también las ideas de libertad, unidad, independencia y, en resumidas cuentas, de patriotismo propias de la España del XIX que ansiaba remontarse a sus raíces más novelescas. Aunque nos encontramos con numerosas escenas sacadas de la Edad Media, de la época de los Reyes Católicos y de la propia contemporaneidad, la permanencia de los episodios de la Antigüedad, como veremos, no llegó a abandonar por completo la pintura, y a menudo los archiconocidos héroes clásicos siguieron siendo adoptados como modelos de virtud.

\section{LAS PINTURAS DE CARÁCTER MITOLÓGICO}

Es uno de los apartados de los que podemos hablar, dentro de ese revival del mundo clásico que contemplamos en el panorama de las artes europeas. Los pintores de comienzos del siglo XIX prestaron mucha atención a los episodios mitológicos de Grecia y de Roma, como no podía ser menos 
en una época en la que los presupuestos del Neoclasicismo seguían estando vigentes. En el caso español, no es necesario rastrear demasiado para encontrar ejemplos como Hércules y Anteo de Rafael Tejeo, Diana en el baño de Francisco Reygon o, ya a comienzos del siglo XX, el Rapto de Europa de Fernando Álvarez de Sotomayor como una prueba de la pervivencia que aún seguían teniendo ${ }^{7}$.

Con la evolución de la centuria asistimos a un cambio relacionado con esta pintura mitológica. Los presupuestos pasados de moda del Neoclasicismo, sumados a la desconfianza subyacente de la Iglesia, que no veía con buenos ojos todos estos despliegues artísticos alrededor de temas considerados paganos, y la progresiva asimilación del nuevo gusto romántico, que prefería remontarse a la Edad Media en lugar de la Antigüedad, consiguieron desplazar la atención de la mayor parte de los artistas a temas más intrínsecamente españoles ${ }^{8}$. Alejados de los amoríos de los dioses, de las genealogías de los héroes de la Ilíada y de las Metamorfosis de Ovidio, los lienzos pasaron a mostrar motivos más trascendentales de nuestra propia historia. Esto no quiere decir que se olvidaran por completo las grandes gestas clásicas, sino simplemente que se adaptaron de manera que pudiera rastrearse documentalmente la evidencia de que formaron parte de nuestra tradición. La dramática muerte de Viriato, y la heroica resistencia de ciudades como Numancia y Sagunto, pasaron a formar parte del peculiar panteón de la pintura de historia con el mismo derecho que las más sonadas campañas de la Antigüedad, por todos conocidas.

No obstante, los acontecimientos que tuvieron lugar en la propia Roma siempre se contaron entre los más representados por parte de los jóvenes pintores pensionados en Italia, antes de centrarse en los propiamente españoles, como veremos a continuación.

\section{LOS TEMAS Y PERSONAJES DE LA ROMA ANTIGUA}

Esta modalidad daba mucho más juego a los artistas, ya que les permitía poner en práctica su maestría y al mismo tiempo demostrar que eran capaces de ceñirse a las circunstancias concretas de un relato, siguiendo al pie de la letra las narraciones contenidas en las fuentes que hemos mencionado. Cuadros con nombre propio, por así decirlo, como Cincinato abandona el arado para dictar leyes a Roma, de Juan Antonio Ribera y Fernández, se convierten en testimonios vivos de un momento de la historia que se retoma como uno más de los modelos ejemplarizantes de cara a la sociedad del XIX. Podemos decir lo mismo de cuadros de carácter más colectivo, como Naumaquia en tiempos de Augusto de Ricardo de Villodas, o más anónimos como Una señora pompeyana en el tocador de Alejo Vera, que dejan un poco de lado la carga moralizante 
para centrarse en los aspectos más anecdóticos de la Antigüedad, tratando de mantenerse fieles al pasado.

Existe también una modalidad, dentro de los cuadros de mayores dimensiones, focalizada en la exposición de un cadáver que por su dramatismo atrae las miradas de los espectadores desde un primer momento. Es lo que sucede con Nerón contemplando el cadáver de su madre Agripina, realizado por Arturo Montero, con el cuerpo desnudo de la madre del emperador destacando nítidamente sobre el paño blanco que recubre su lecho mortuorio, en un escorzo muy académico. Es una de las escasas representaciones de la vida de Nerón que encontramos en la pintura de historia del XIX, ya que se había pasado de moda, por así decirlo, después del apogeo que este tema experimentó durante el período artístico conocido como pompier. El asesinato de Julio César se convirtió en un motivo mucho más recurrente, con diferentes momentos pertenecientes al mismo ciclo como El sueño de Calpurnia de Luis Álvarez Alcalá (en el cual la esposa de César se ve asaltada por la premonición de que lo asesinarán en el Senado), la propia Muerte de Julio César de Ricardo de Villodas (el instante más dramático, con una composición semicircular en la cual los miembros del Senado y los partidarios de Bruto rodean a la figura central del protagonista) y por último Marco Antonio presentando al pueblo el cadáver de César de José Arpa Perea (siendo las veintitrés puñaladas el testimonio más palpable de la necesidad de plantar cara al despotismo). El mensaje seguía siendo el mismo en todos los cuadros, y además inequívoco: el abuso desmedido de poder acabará llevando al ser humano a la más despiadada violencia por parte de quienes aún creía tener de su parte.

La dramática muerte de Lucrecia, fruto de la violación perpetrada contra su persona por parte del hijo de Tarquinio el Soberbio, un ultraje que provocó la caída de la monarquía romana, se mantenía en la misma estela sirviendo como denuncia contra el despotismo. Contamos con tres lienzos realizados por pintores de historia españoles durante el siglo XIX, recreándose en la narración de Tito Livio de los que fueron los últimos momentos de la dama patricia. El primero, realizado por José de Madrazo, carece de la vis poetica que encontramos en las composiciones de sus sucesores, especialmente en la realizada por Eduardo Rosales en 1871. Su Muerte de Lucrecia volvió a revolucionar el panorama de la pintura española como lo había hecho años antes con su Doña Isabel la Católica dictando su testamento, pues los temas de la Antigüedad, como dijimos en su momento, carecían en la segunda mitad del siglo XIX de la importancia que habían tenido en sus primeras décadas, de manera que la representación de Rosales actuó como una especie de revulsivo entre los artistas más jóvenes. Considerada por el propio artista como su mejor obra, se aparta de Tito Livio en cuanto al emplazamiento de la escena para situarse en un interior doméstico, acentuando el carácter de tragedia familiar del acontecimiento que acabó con la honradez de Lucrecia, y con su 
vida. Si bien es cierto que los pinceles de Rosales se ven poseídos por una extraordinaria franqueza en cuanto a la factura y el empastado de la pintura, el moderno tratamiento de la misma no impide que se recree en la abundancia de detalles históricos de un interior cuidado hasta en sus menores detalles,

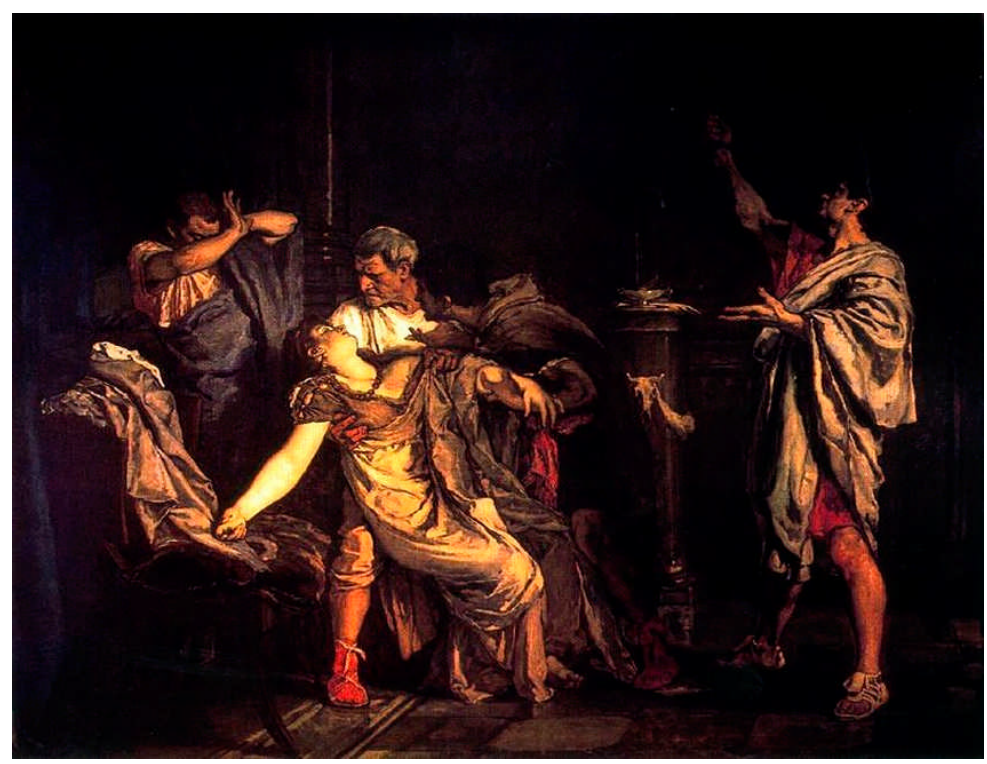

[Fig. 1] Muerte de Lucrecia, Eduardo Rosales, 1871.

de lo que dan buena cuenta los tejidos, los muebles y la propia arquitectura.

Más adelante Casto Plasencia regresó sobre el mismo tema, aunque al sacar la representación de la muerte de Lucrecia a la plaza pública, más en consonancia con el texto de Tito Livio, consigue devolver al episodio su carácter de denuncia política y de incitación a la revuelta contra la monarquía. La escena deja de ser familiar para convertirse en un asunto de Estado; el propio título del cuadro, Origen de la República Romana (año 598 antes de la era cristiana), se aparta de la tragedia de la protagonista para devenir en uno de los acontecimientos más importantes de la Historia de Roma. La composición también ha cambiado, ampliando el punto de vista por encontrarnos en un exterior que convierte al espectador en uno más de los ciudadanos romanos. La identificación de la escena con la realidad política de la nación se ha llevado a sus últimas consecuencias. 


\section{LOS TEMAS Y PERSONAJES DE HISPANIA}

Aunque de menor importancia, en comparación con los grandes temas y ciclos de la Roma clásica que acabamos de mencionar, se encuentran los cuadros que representan episodios de la vida de personajes nacidos en territorio hispano. A la virtud encarnada por cada uno de ellos se sumaba el atractivo de que resultaran, a los ojos de nuestra nación, genuinos representantes del supuesto carácter español ${ }^{9}$ por el que se nos conocía al otro lado de los Pirineos. La valentía, la hombradía, la rectitud moral, se interpretaron como cualidades necesariamente extrapolables a la moderna sociedad española. Así, los pintores encontraron en los momentos de mayor dramatismo de las vidas de estos personajes una inmejorable excusa para establecer lo que, en palabras de Pérez Vejo, entendían como la genealogía de nuestra cultura, la exaltación del alma nacional ${ }^{10}$.

La muerte de Lucano, presentada por José Ramón Garnelo y Alda en la Exposición Nacional de 1866, se puede encuadrar dentro de esta vertiente de marcada raigambre nacional. La dramática muerte del poeta cordobés de veinticinco años, incorporado por Nerón a su cohors amicorum en el año $54 \mathrm{~d}$. de C., para después decretar su muerte tanto por celos de su talento como por considerarlo partícipe de una conspiración contra su persona, se tomó como un modelo de referencia muy similar al ejemplificado por su tío Séneca el Viejo. Garnelo regresó años más tarde sobre este mismo tema pictórico, con un nuevo lienzo de 1887 más alabado por la crítica debido a su composición más realista que no era óbice, no obstante, para el habitual despliegue de gestos grandilocuentes de dolor. Sus fuentes fueron las mismas en ambos casos: la narración de Suetonio y la obra de Castelar Lucano, su vida, su genio, su poema. Similar en cuanto a su composición, y su aliento moral, resulta La muerte de Séneca realizada en 1871 por Manuel Domínguez Sánchez, así como la versión de Enrique Valls presentada a la misma exposición en la que participó Garnelo con su segundo Lucano, en 1887. No obstante, La muerte de Viriato, realizada por José de Madrazo en la temprana fecha de 1808, siempre se considerará uno de los hitos más destacados de esta modalidad.

Fue realizado como la primera de una serie de grandes lienzos de tema profundamente patriótico, planeados por Madrazo durante su estancia en Roma ${ }^{11}$. El caudillo lusitano, siguiendo la composición más recurrente, aparece tendido en su lecho mortuorio, rodeado por los soldados reunidos en su tienda de campaña, cuyos rostros comprenden todo un abanico de pesar. Estas expresiones tan teatrales, así como la monumentalidad y la grandiosidad del conjunto, convierten al cuadro en uno de los principales exponentes del Neoclasicismo español. Pese a todo, ya en su momento se le hicieron ciertas críticas relacionadas con la escasa naturalidad de las actitudes de los personajes, así como con la composición en friso, algo muy común en la pintura de historia, que no consigue ocultar la marcada inspiración de Madrazo en 
una ilustración realizada por John Flaxman para la publicación de La Ilíada en $1793^{12}$. La influencia de los bajorrelieves que solían decorar la parte frontal de los sarcófagos romanos será determinante para ambos artistas.

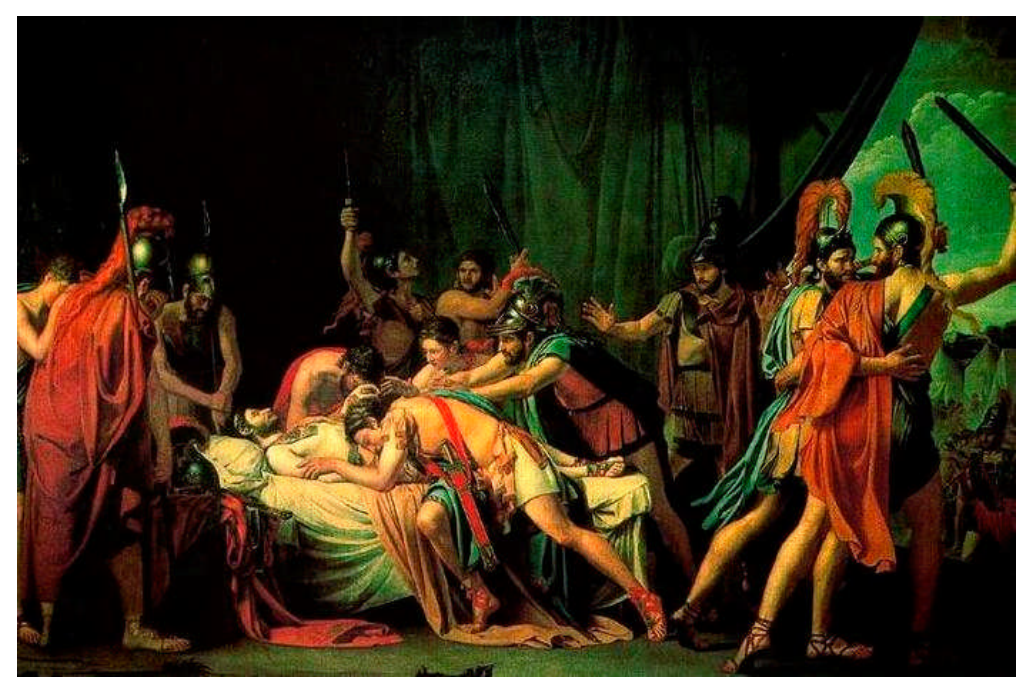

[Fig. 2] La muerte de Viriato, José de Madrazo, 1808.

Viriato, en una época en la que España se sentía ultrajada por los asaltos de las tropas de Napoleón, se interpretó como la personificación de la independencia, la lucha por la libertad de un pueblo capaz de plantarle cara a su opresor. Pero la resistencia patriótica no fue el único tema sobre el que trabajaron varios artistas al mismo tiempo; también la abstinencia se elevó sobre las alas de la virtud en las representaciones de La continencia de Escipión. Recogen el momento en que el general romano, de quien era sabido que sentía debilidad por el bello sexo, renuncia a sus derechos sobre una prisionera de guerra a la que devuelve a su padre, acompañada por el rescate que éste había pagado para que le sirviera como dote de cara a su matrimonio. Este tema, encuadrado en el marco bélico de la toma de Qart-Hadast, y su posterior conversión en Cartago Nova, había inspirado a numerosos pintores como Pinturicchio, Giovanni Bellini y Anton Van Dyck ${ }^{13}$, y ya en la centuria que nos ocupa a José Ribelles y a Federico de Madrazo, hijo de José de Madrazo. Posiblemente su versión sea la más conocida, realizada en Roma cuando no contaba más que dieciséis años, un punto a su favor a la hora de ingresar en la Real Academia de Bellas Artes de San Fernando, y planteada de nuevo con una notable sumisión a los presupuestos del Neoclasicismo que apostaba por composiciones planas, a modo de frisos. 


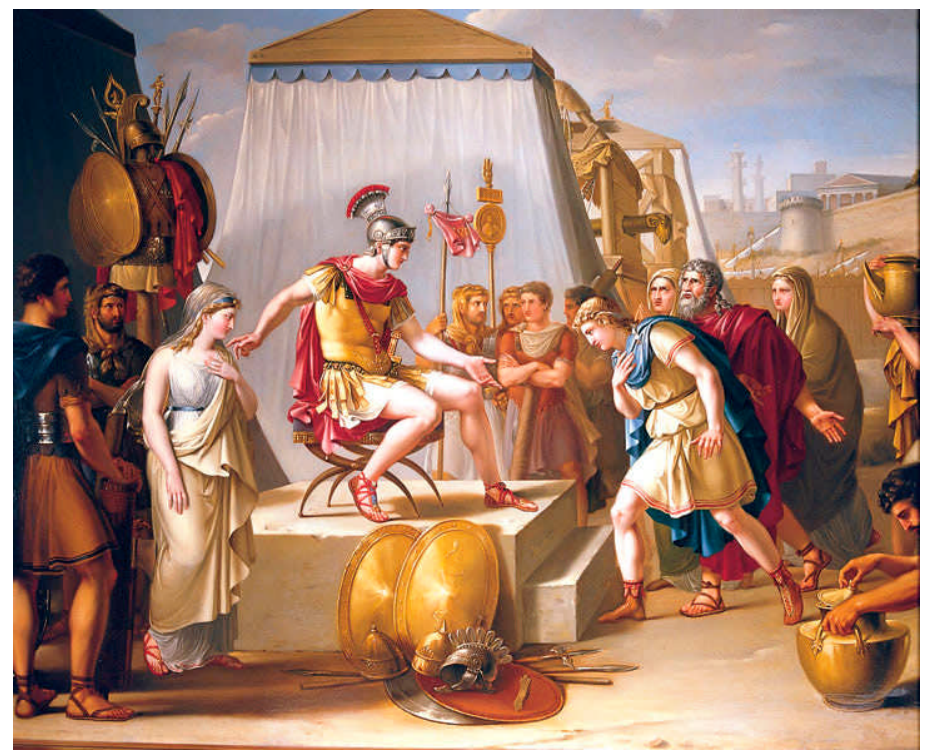

[Fig. 3] La continencia de Escipión, Federico de Madrazo, 1831.

Pero serán las composiciones más grandilocuentes, centradas en la caída de Sagunto y de Numancia, las que encarnarán a la perfección las ansias de reafirmación nacional de España. Fueron las que más páginas de la prensa acapararon en su momento, las más ambiciosas a la hora de plasmar el heroísmo de un pueblo que, al borde de la muerte y la destrucción, consigue convertirse en un imperecedero símbolo de nuestra valentía. Vicente Jimeno fue el primero en realizar una pintura de historia sobre Numancia, presentándola en la Exposición de la Academia de 1842; posteriormente Rafael Enríquez, Ramón Martí Alsina y Alejo Vera y Estaca retomaron el mismo tema. En el caso de Alsina, aunque su obra no consiguiera ningún premio, alcanzó un notable reconocimiento al ser adquirida por el Estado para adornar las paredes del Palacio del Senado. Resulta pese a todo un poco retardataria, algo lógico teniendo en cuenta que se realizó en 1858, en un momento en que los ecos clasicistas aún se encontraban muy presentes dentro de este género. Más atrevida, y más difundida por parte de la prensa, resultó la versión de Vera y Estaca de Numancia de 1881. En su caso les concede más importancia a las ruinas humeantes que Alsina, quien centraba su composición en las poderosas contorsiones y las musculosas anatomías de los numantinos. Aquí se representa el momento en que los invasores consiguen irrumpir en la ciudad sitiada, únicamente para presenciar los últimos estertores de un pueblo capaz de autoinmolarse antes que deponer sus armas ante Roma. 


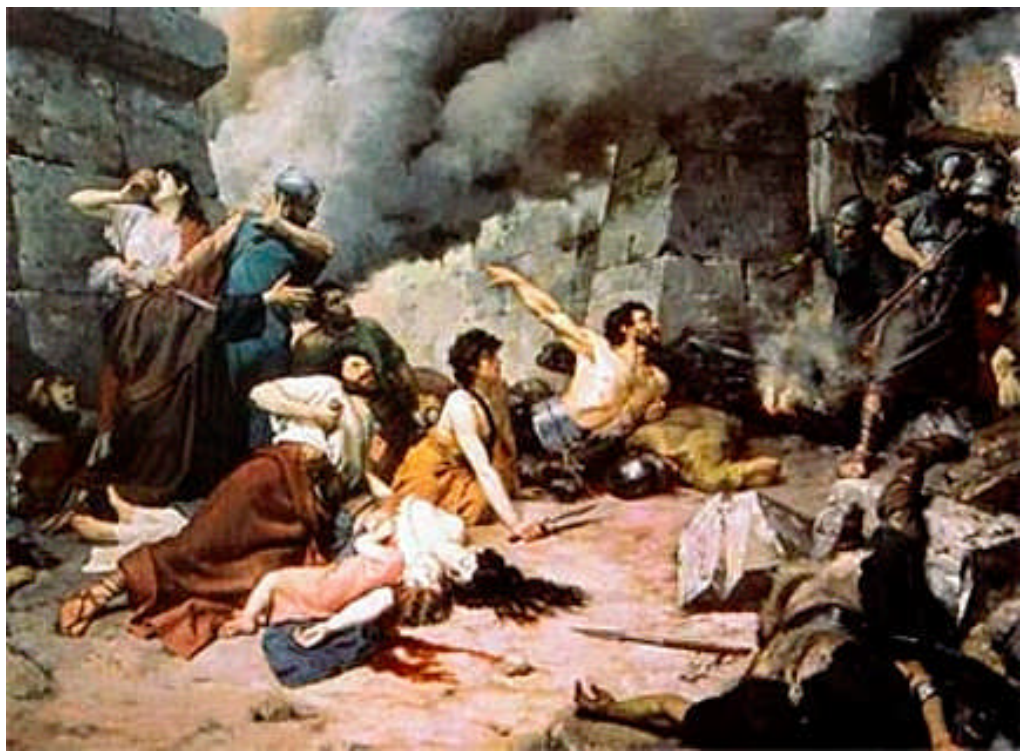

[Fig. 4] Numancia, Alejo Vera y Estaca, 1881.

También la caída de Sagunto se convirtió en un símbolo del arrojo español, por los mismos motivos que Numancia. Sin embargo, su aparición en el panorama de la pintura de historia es mucho más tardía que la de los temas anteriormente mencionados, y con mucha menor entidad, puesto que no contamos más que con dos lienzos sobre el particular ${ }^{14}$. María Soledad Garrido y Agudo realizó un Sacrificio de las saguntinas que no obtuvo mayor reconocimiento en las exposiciones, puesto que prefería centrarse en un particular del hecho histórico en lugar de abrazar su momento más dramático, al modo de lo que llevó a cabo Francisco Domingo Marqués. Su Último día de Sagunto se mostró en la Exposición Nacional de 1871, siendo especialmente alabados sus juegos de luces y sombras, su virtuosismo a la hora de plasmar la humareda que recubre los restos de las construcciones y su composición en diagonal, que recuerda a La balsa de la Medusa de Géricault ${ }^{15}$.

En este caso no son las huestes romanas las que rompen el cerco de la ciudad, sino las cartaginesas, con Aníbal en persona a la cabeza, aunque la intención moral de la obra sigue siendo la misma: la plasmación de un modelo de valentía intrínsecamente español que permitiera concienciar a las nuevas generaciones de cómo debían honrar a su patria. 


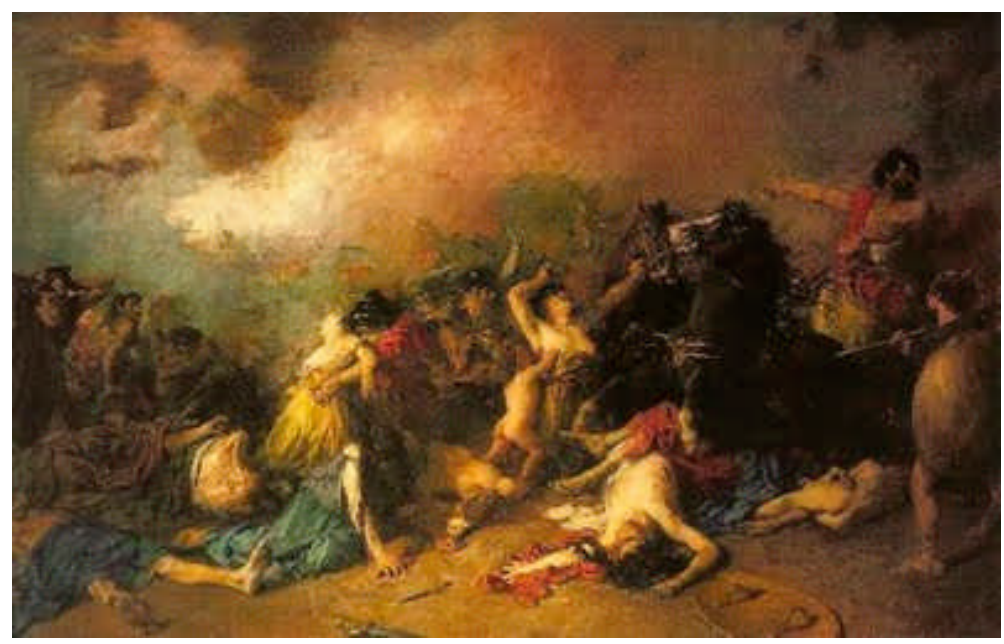

[Fig. 5] Último día de Sagunto, Francisco Domingo Marqués, 1869.

\section{LA ANTIGÜEDAD EN EL CAMPO DE LA ESCULTURA}

Aunque se sale del marco del presente estudio, no queremos concluir nuestro breve recorrido por el panorama de las artes españolas del siglo XIX sin prestar atención a su escultura. Los temas de la Antigüedad se encuentran presentes en muchas de las obras que se emprendieron a comienzos de la centuria, como no podía ser menos por herencia del clasicismo, pero también en la época en que se realizaron las grandes composiciones pictóricas que acabamos de mencionar. Contamos con numerosas representaciones mitológicas como el delicado grupo de Venus y Cupido realizado por José Ginés, el Ganimedes de José Álvarez Cubero, considerado el mayor representante del Neoclasicismo español, y la Eurídice mordida por un áspid de Sabino de Medina ${ }^{16}$. Pero también nos encontramos con escenas conocidas por nosotros como La muerte de Lucrecia, que llevó a cabo el catalán Damià Campeny como un boceto en yeso durante su pensionado en Roma, en 1804, y que trasladó al mármol tres décadas después. El abandono del cuerpo de la ultrajada protagonista, y su sensual y al mismo tiempo grácil morbidez, hablan bien a las claras de la influencia ejercida por Antonio Canova, el más importante de los escultores neoclásicos ${ }^{17}$. La presencia de temas de la Antigüedad vuelve a estar presente en la escultura conmemorativa, un género muy en boga en el siglo XIX pero que debido a su afán de ejemplificación inmediata, de asimilación de la sociedad con un personaje concreto, prefería centrarse en las escenas sacadas de la propia contemporaneidad antes que en las del mundo clásico. Aún así, tenemos monumentos como el de Julio Moderato Columela de Cádiz, escritor agronómico romano de principios de la era cristiana, y el 
más conocido de Viriato de Zamora. El caudillo lusitano vuelve a convertirse en un modelo de valentía al plantar cara a los invasores, adoptando un tipo atlético, plenamente greco-romano, muy alejado de las caracterizaciones más rústicas de los primitivos indígenas ${ }^{18}$.

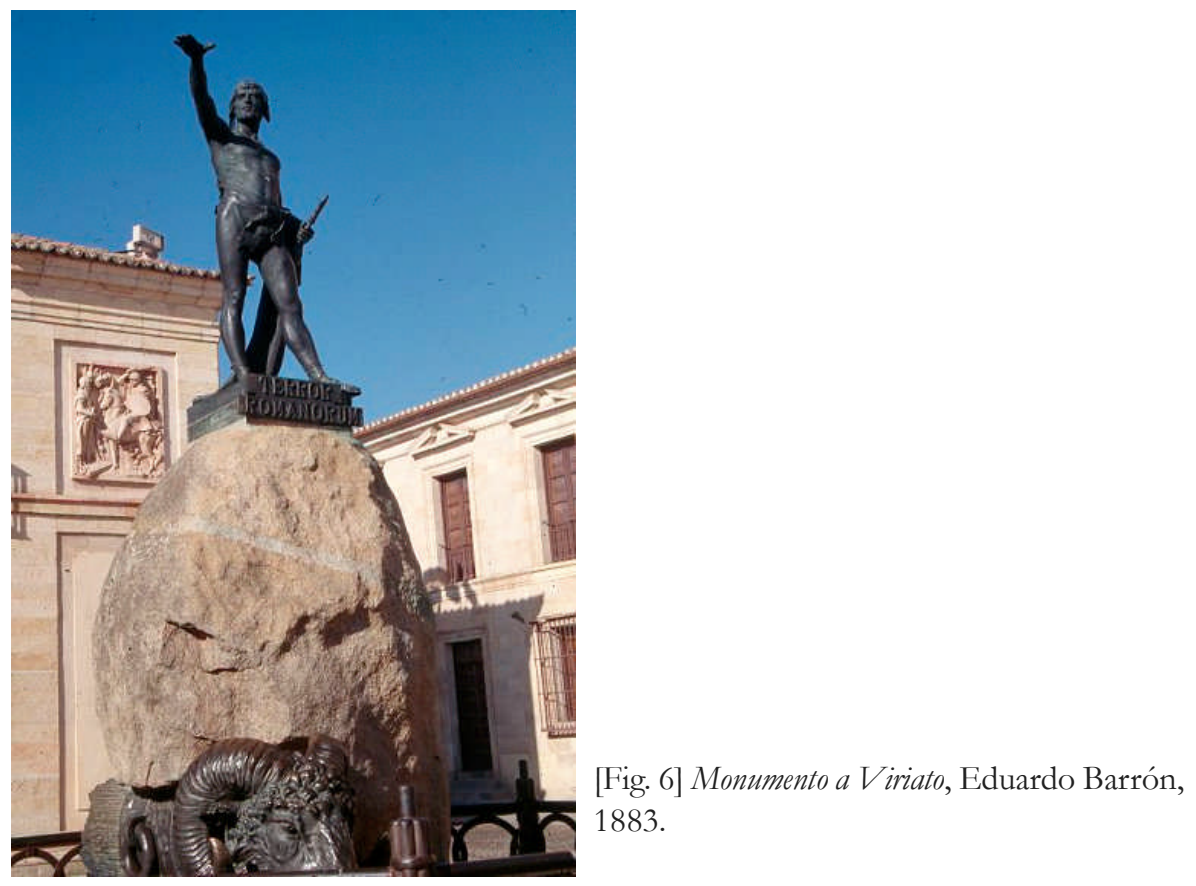

De esta manera, como hemos tenido ocasión de comprobar en nuestro recorrido, la Antigüedad perteneciente a la Historia de España, la de nuestro propio pasado y nuestro particular panteón de héroes, tan inmortales como los de la misma Roma, dejó de usarse como un mero divertimento por parte de los artistas, para pasar a ser un medio de darle vida a las ansias patrióticas del Romanticismo. La identidad de la nación cobraba vida en los lienzos, de la mano de personajes que habían demostrado, muchos siglos atrás, la misma nobleza que se trataba de insuflar en los corazones de los españoles. Los valores de la perseverancia, la valentía y la honradez se ataviaban con vestiduras greco-romanas y se tornaban tan reconocibles como cualquiera de los héroes del siglo XIX, una galería de hombres y mujeres suspendidos para siempre entre el pasado, el presente y el futuro. 


\section{Notas}

${ }^{1}$ La conocida escultura helenística del sacerdote troyano ahogado por unas serpientes, junto con sus hijos, fue encontrada en 1506 entre las ruinas de la Domus Áurea de Nerón. Miguel Ángel fue uno de los artistas que asistieron a su descubrimiento, reconociéndolo como el grupo escultórico que Plinio el Viejo definió en su Naturalis Historiae como "la mejor obra artística de la pintura y de la escultura juntas". TAZARTES, Maurizia, Las obras maestras. El Greco, Madrid, Unidad Editorial S.A., 2005, pág. 168.

${ }^{2}$ Sobre la iniciativa española al respecto, consultar FERNÁNDEZ MURGA, Félix, Carlos III y el descubrimiento de Herculano, Pompeya y Estabia, Salamanca, Ediciones Universidad de Salamanca, 1989.

${ }^{3}$ REYERO, Carlos, La pintura de bistoria en España. Esplendor de un género en el siglo XIX, Madrid, Cátedra, 1989, págs. 38-39.

${ }^{4}$ MENDOZA, Francisco de, Manual del pintor de historia, Madrid, Imprenta de Fortanet, 1870, págs. 31-32. Cfr. en REYERO, Carlos, op. cit., pág. 37.

${ }^{5}$ PICÓN, Jacinto Octavio, "La Exposición de Bellas Artes" en El Correo, 3 de junio de 1884. Cfr. en PÉREZ VEJO, Tomás, Pintura de historia e identidad nacional en España, Madrid, Ediciones de la Universidad Complutense de Madrid, 1996, pág. 527.

${ }^{6}$ CASADO DEL ALISAL, José, Discursos leidos ante la Real Academia de Bellas Artes de San Fernando en la recepción pública del Excmo. Sr. D. José Casado del Alisal el día 15 de noviembre de 1885, Madrid, Imprenta de Fortanet, 1885, pág. 21. Cfr. en REYERO, Carlos, op. cit., pág. 35.

${ }^{7}$ VIÑUALES GONZÁLEZ, Jesús, "La pintura de historia en España. Tipología y clasificación” en Espacio, tiempo y forma, Serie VII, Historia del arte, n 1, 1998, pág. 240.

${ }^{8}$ En palabras de Tomás Pérez Vejo, se pretendía "despojar poco a poco a la historia nacional de aquellos elementos más fabulosos y míticos, acortando los antiguos orígenes hasta retrotraerlos a aquellos pueblos cuya existencia estaba documentada por los escritores clásicos, principalmente romanos". PÉREZ VEJO, Tomás, op. cit., pág. 508.

${ }^{9}$ PÉREZ VEJO, Tomás, op. cit., pág. 541.

${ }^{10}$ PÉREZ VEJO, Tomás, ibidem.

${ }^{11}$ Parece que la invasión napoleónica fue una de las causas que le llevaron a emprender esta ambiciosa labor pictórica, que debía estar formada por La muerte de Viriato, Los funerales de Viriato, Megara obliga a los romanos a capitular y La destrucción de Numancia; éste fue el único que José de Madrazo pudo concluir. VV. AA., La pintura de bistoria del siglo XIX en España, Madrid, Consorcio Madrid'92, 1992.

${ }^{12}$ Esta similitud se apuntó en el siglo XIX en OSSORIO Y BERNART, Manuel, Galería biográfica de artistas españoles del siglo XIX, Madrid, Imprenta de Moreno y Rojas, pág. 398, aunque se ha profundizado en fecha más reciente sobre esta cuestión, en ARIAS ANGLÉS, Enrique, "Influencias de John Flaxman y Gavin Hamilton en José de Madrazo y una nueva lectura de La muerte de Viriato" en Archivo Español de Arte, t. 53, 1985, págs. 351-362.

${ }^{13}$ Sobre la influencia ejercida por este último lienzo sobre los pintores españoles, remitimos a DÍAZ PADRÓN, Matías, "La continencia de Escipión de Van Dyck, del Alcázar de Madrid, identificada en la Christ Church de Oxford” en Goya: Revista de arte, $n^{\circ} 311,2006$, págs. 8594.

${ }^{14}$ PÉREZ VEJO, Tomás, op. cit., pág. 540. 
${ }^{15}$ Sobre este punto, GRACIA BENEYTO, Carmen, "Anotaciones históricas y documentales sobre El último día de Sagunto de Francisco Domingo Marqués" en Archivo de Arte Valenciano, 1981, pág. 109.

${ }^{16}$ RINCÓN GARCÍA, Wifredo, "Escultura del siglo XIX" en Cuadernos de Arte Español, $n^{\circ}$ 66, Madrid, Grupo 16, págs. 7-23.

${ }^{17}$ Acerca de la labor escultórica de Campeny, CID PRIEGO, Carlos, La vida y la obra del escultor neoclásico catalán Damià Campeny i Estrany, Barcelona, Caixa Laietana, 1998.

${ }^{18}$ Conviene recordar que el conocido monumento a Viriato no puede considerarse una escultura de carácter conmemorativo en cuanto a su configuración, sino que obedece simplemente al deseo de convertir en elemento de la ornamentación urbana de Zamora un original en yeso realizado por Eduardo Barrón, y adquirido por el Estado. REYERO, Carlos, La escultura conmemorativa en España: la edad de oro del monumento público, 1820-1914, Madrid, Cátedra, 1999, págs. 136-137. 